\title{
Estimation of Point Daylight Factor (PDF) Average Daylight Factor (ADF) and Vertical Daylight Factor (VDF) under various obstructed CIE Standard Skies
}

\author{
Shuyang LI ${ }^{1}$, Danny H W LI ${ }^{1}$, Wenqiang CHEN ${ }^{1}$ \\ ${ }^{1}$ Building Energy Research Group, Department of Architecture and Civil Engineering, City \\ University of Hong Kong, Tat Chee Avenue, Kowloon, Hong Kong SAR, China
}

\begin{abstract}
Estimation of the daylight level for any point within an interior space is essential to daylighting designs and assessments. In 2003, the CIE adopted a range of 15 skies as international standard models that represent the actual skies of many places and cover the whole probable spectrum of skies. In many urban cities, the external obstructions may significantly reduce the amount of daylight entering to the indoor space. Previously, we developed a number of calculation tools to predict daylight illuminance for rooms facing different orientations under various CIE Standard Skies. This paper presents the work on the calculation of the PDF, ADF and VDF under various overcast and non-overcast obstructed skies. Calculation procedures are demonstrated. Characteristics of the findings and design implications are discussed.
\end{abstract}

Keywords: CIE Standard Skies; Point Daylight Factor; Average Daylight Factor; Vertical Daylight Factor;

\section{Introduction}

In Hong Kong, most buildings are high-rise constructed in densely built business districts and the shading effect from nearby buildings is very significant ( $\mathrm{Li}$ et al., 2006). This could restrict the quantity of daylight and solar-heat penetrating into the building interior, especially for rooms located in lower floors. Therefore, estimation of the daylight level for any point within an interior space is essential to daylighting designs and assessments ( $\mathrm{Li}, 2010)$. The usual method for computing natural illuminance for a given location in a building is the daylight factor (DF) approach, which based on the traditional overcast sky without sunlight, as defined by the International Commission on Illumination (CIE). The DF approach can be analytically calculated using simple design aids and annual daylight data are not required. The point daylight factor (PDF) has shown the effectiveness of daylightlinked controls in saving energy on electric lighting (Yu and Su, 2015). The average daylight factor (ADF), which is directly related to window area and less detailed input data than those provided by the PDF, could be a useful daylighting criterion (Lynes and Littlefair, 1990). The vertical daylight factor (VDF) representing light coming directly from the sky and daylight reflected from surrounding buildings and the ground onto a vertical surface has been appropriately used for compact urban areas with large exterior obstructions, such as Hong Kong (Cheung and Chung, 2005). Practitioners have become accustomed to using the daylight criteria that are usually expressed in the DF approach, which has been adopted in many countries (Hraska, 2011). However, such DF approaches are not flexible enough to predict the dynamic daylight variations caused by the sun movement on nonovercast skies (Littlefair, 1989; Perez et al., 1993). Therefore, the daylight metric based on the DF lacks realism. In 2003, the CIE adopted a range of 15 skies as international standard models (CIE, 2003; ISO,2004) that represent the skies of many places and cover the complete probable spectrum of skies found in nature (Li et al., 2003). DFs have good correlation with building daylight designs. Previously, we calculated the correlations between the three DFs under various non-obstructed CIE Standard Skies (Li et al., 2018). This paper presents the work on the calculation of the PDF, ADF and VDF under the 15 obstructed CIE skies. Calculation procedures are demonstrated. Characteristics of the findings and design implications are discussed.

\section{Proposed Methodology}

The DF for an internal space is often split into three components, namely the sky component (SC), the externally reflected component (ERC) and internally reflected component (IRC) (Hopkinson et al., 1966).

$$
\mathrm{DF}=\mathrm{SC}+\mathrm{ERC}+\mathrm{IRC}
$$

The computation of the IRC can be based on the theory of the split-flux principle given as:

$$
\mathrm{IRC}=\operatorname{tW}\left(\frac{C R_{f w}+D R_{C w}}{A(1-R)}\right)
$$

where $A$ is the total area of all the interior surfaces, $\mathrm{m}^{2} ; C$ and $D$ are the configuration factors of the daylight flux incident on the mid-height of the window pane from above and below the horizon, respectively, dimensionless; $R$ is the average reflectance of all the interior surfaces, dimensionless; $R_{c w}$ is the average reflectance of the ceiling and upper walls above the mid-height of the window, excluding the window wall, dimensionless; $R_{f w}$ is the average reflectance of the floor and lower parts of the walls below the mid-height of the window, excluding the window wall, dimensionless; $t$ is the visual transmittance of the window, dimensionless; $W$ is window area, $\mathrm{m}^{2}$.

Further, the luminance levels and patterns of the sky in the direction of views of the surface mainly influence the daylight illuminance incident on a window façade. An appropriate approach of determining the diffuse 
illuminance on an inclined plane is to compute the luminance distribution of the sky dome seen by the plane (Kittler and Darula, 2006). Recently, we developed calculation tools for computing the daylight illuminance falling on a vertical surface of a building (VDI) and VDF (Li et al., 2017). The VDI and VDF are useful data for justifying the daylighting performance of the building facing large external obstructions. The SC and ERC for an interior reference point can be estimated from the corresponding VDI/VDF using the configuration factor principle. Figure 1 shows such the configuration factor for a vertical rectangle surface to a horizontal point ( $\left.\mathrm{cf}_{\mathrm{vh}}\right)$ (IES, 1993).

$$
=\frac{1}{\pi}\left(\arctan \frac{1}{Y}-\frac{Y}{\sqrt{X^{2}+Y^{2}}} \arctan \frac{1}{\sqrt{X^{2}+Y^{2}}}\right)
$$

where $\mathrm{X}=\mathrm{L}_{1} / \mathrm{L}_{2} ; \mathrm{Y}=\mathrm{L}_{3} / \mathrm{L}_{2}$

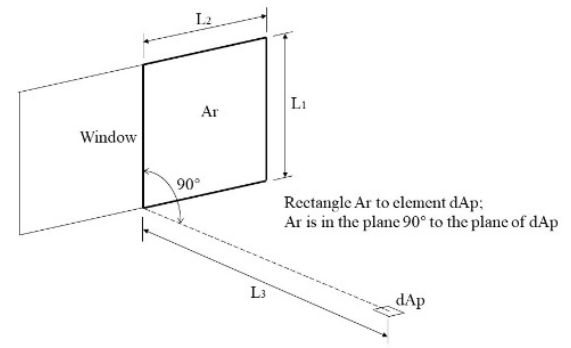

Figure 1: Layout of the configuration factor between $d A_{p}$ and $A_{r}$.

VDF takes into account light coming directly from the sky and reflected daylight from surrounding buildings and ground both above and below the horizon onto a vertical surface of a building. Mathematically, the VDF can be written as: (Li et al, 2009)

$$
\mathrm{VDF}=\frac{E_{S}+E_{r b}+E_{r g}}{E_{h}}=\mathrm{C}+\mathrm{D}
$$

where $E_{s}$ is the sky-diffuse illuminance coming directly from the sky (lux) (overcast skies); Erb is the reflected light from obstructing buildings (lux); $\mathrm{E}_{\mathrm{rg}}$ is the reflected light from ground (lux); $\mathrm{E}_{\mathrm{h}}$ is the horizontal illuminance of an unobstructed sky (lux).

The average daylight could be a useful daylighting criterion. The basic equation given by Longmore for the average daylight factor is expressed as:

$$
\mathrm{ADF}=\mathrm{tW}\left(\frac{C}{A_{f w}}+\frac{C R_{f w}+D R_{C w}}{A(1-R)}\right)
$$

where $A_{f w}$ is the area of the floor and lower parts of the walls below the mid-height of the window, excluding the window wall $\left(\mathrm{m}^{2}\right)$.

The important issue is to determine the configuration factors $\mathrm{C}$ and $\mathrm{D}$ under various obstructed sky conditions. Mathematically, C and D can be written as (Li et al., 2012):

$$
\begin{aligned}
& \mathrm{C}=\mathrm{Es}+\left(\mathrm{E}_{\mathrm{rba}} / \mathrm{E}_{\mathrm{h}}\right) \\
& \mathrm{D}=\left(\mathrm{E}_{\mathrm{rbb}}+\mathrm{E}_{\mathrm{rg}}\right) / \mathrm{E}_{\mathrm{h}} \\
& \mathrm{E}_{\mathrm{rb}}=\mathrm{E}_{\mathrm{rba}}+\mathrm{E}_{\mathrm{rbb}}
\end{aligned}
$$

where $E_{r b a}$ is the reflected daylight from buildings above the horizon (lux); $E_{\text {rbb }}$ is the reflected daylight from buildings below the horizon (lux).
Es is the obstructed vertical sky component (OVSC). The regression equation between OVSC and $\chi$ at various $\alpha_{U}$ was developed and is shown in Eq.9. Appendix 1 presents the coefficients $a_{0}, a_{1}, b_{1}, a_{2}, b_{2}, c_{0}, d_{1}, d_{2}$ and $\omega$ for the 15 CIE Standard Skies. Accordingly, the OVSC can be computed as (Lou et al., 2016):

$$
\begin{aligned}
& \text { OVSC }=\left[a_{0}+a_{1} \cos (\chi \omega)+b_{1} \sin (\chi \omega)+a_{2} \cos (2 \chi \omega)+\right. \\
& \left.b_{2} \sin (2 \chi \omega)\right]\left[\frac{1}{1+\exp \left(c_{0}+d_{1} \chi+d_{2} \alpha_{U}\right.}\right]
\end{aligned}
$$

A comparative study was conducted using the results determined by a lighting simulation program namely Radiance which has been used by a number of researchers to computer interior illuminances and DFs.

\section{Model for estimating DF}

An infinite-length urban canyon (as shown in Figure 2) was used in the present study. The model represents a typical skyline feature of densely built cities, which was adopted by many researchers to examine urban daylight. As shown in the figure, $a_{U}$ is the upper obstructed angle; $a_{L}$ is the lower obstruction angle; $a_{b}$ is the building obstruction angle. $\phi_{N}$ is the azimuth angle of the normal direction of the vertical fenestration and $\phi_{N}$, is the azimuth angle of the normal direction of obstruction.

The PDF, ADF and VDF under the 15 obstructed CIE Standard Skies were estimated based on the following conditions. The vertical window area of $2 \mathrm{~m}(\mathrm{~W}) \times 4 \mathrm{~m}(\mathrm{H})$ with the sill height of $1 \mathrm{~m}$ off the floor was set. Figure 3 presents the layout of the room and the reference points for estimating the DF. The centre of the vertical window faces south (sun-shading vertical surface) on 21 December (winter solstice) solar noon $\left(\alpha_{s}=44.3^{\circ}\right.$ and $\left.\phi_{s}=180^{\circ}\right)$ with wall reflectance 0.5 , ceiling reflectance 0.8 and ground reflectance 0.2 under $15 \mathrm{CIE}$ obstructed $\left(\alpha_{U}=15^{\circ} ; \alpha_{U}=30^{\circ}\right.$; $\alpha_{U}=45^{\circ}$ ) skies.

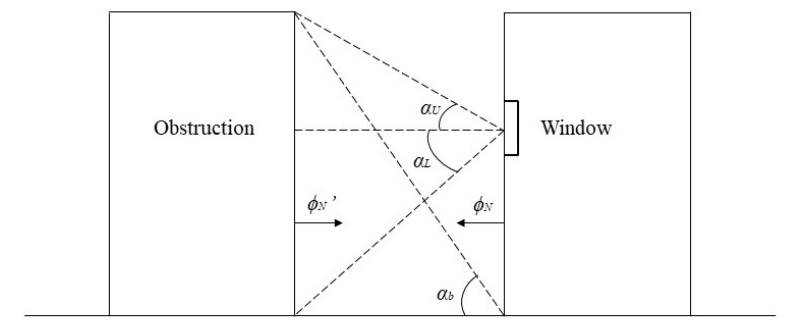

Figure 2: The infinitively long building and obstruction model.

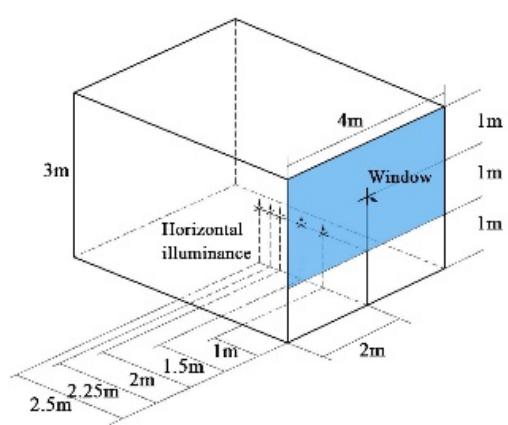

Figure 3: The room layout and the reference points. 


\section{Result Analysis}

The modeled and simulated horizontal illuminance data under the $15 \mathrm{CIE}$ obstructed skies with $\alpha_{U}=30^{\circ}$ at the 5 points are plotted in Figure 4. Five linear trends between the SMI and MHI are evident. The $\mathrm{R}^{2}$ for all regression curves are greater than 0.91 indicating that the modeled and simulated findings are strongly correlated. Table 2 summarizes the ratios of SHI to $\mathrm{MHI}$ and their corresponding $\mathrm{R}^{2}$ under the 15 obstructed $\left(\alpha_{\mathrm{U}}=15^{\circ}, 30^{\circ}\right.$ and $\left.45^{\circ}\right)$ CIE Standard Skies. The mean ratios of simulated to modeled results (SHI/MHI) reduce from 1.16 to 0.27 at the points of $1 \mathrm{~m}$ and $2.5 \mathrm{~m}$ under $\alpha_{\mathrm{U}}=45^{\circ}$. It means that when the point is near to the window, it can view certain amount of sky. As the points move away from the window, the ERC becomes dominant and the ratios drop.

Table 1: The correlation coefficients and $R^{2}$ at the 5 points under various sky obstructions.

\begin{tabular}{|c|c|c|c|c|c|c|}
\hline \multirow{2}{*}{$\begin{array}{l}\text { Distanc } \\
\text { e from } \\
\text { the } \\
\text { window }\end{array}$} & \multicolumn{2}{|c|}{$\alpha_{U}=15^{\circ}$} & \multicolumn{2}{|c|}{$\alpha_{U}=30^{\circ}$} & \multicolumn{2}{|c|}{$\alpha_{U}=45^{\circ}$} \\
\hline & $\begin{array}{l}\text { SHI/ } \\
\text { MHI }\end{array}$ & $\mathbf{R}^{2}$ & $\begin{array}{l}\text { SHI/ } \\
\text { MHI }\end{array}$ & $\mathbf{R}^{2}$ & $\begin{array}{l}\text { SHI/ } \\
\text { MHI }\end{array}$ & $\mathbf{R}^{2}$ \\
\hline $1 \mathrm{~m}$ & 1.18 & 0.98 & 1.26 & 0.99 & 1.16 & 0.95 \\
\hline $1.5 \mathrm{~m}$ & 1.17 & 0.98 & 1.23 & 0.99 & 0.98 & 0.92 \\
\hline $2 \mathrm{~m}$ & 1.16 & 0.97 & 1.14 & 0.96 & 0.63 & 0.92 \\
\hline $2.25 \mathrm{~m}$ & 1.15 & 0.97 & 1.07 & 0.91 & 0.28 & 0.77 \\
\hline $2.5 \mathrm{~m}$ & 1.14 & 0.96 & 0.88 & 0.92 & 0.27 & 0.77 \\
\hline
\end{tabular}

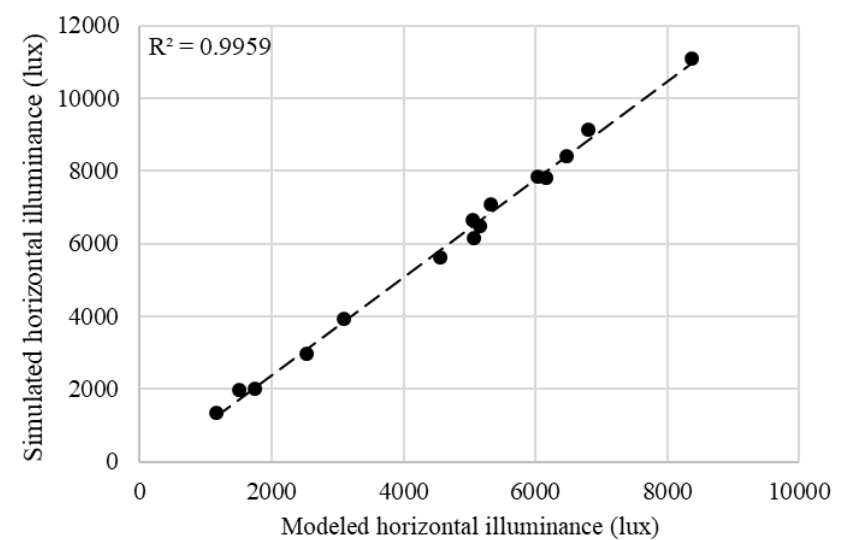

(a)



(b)

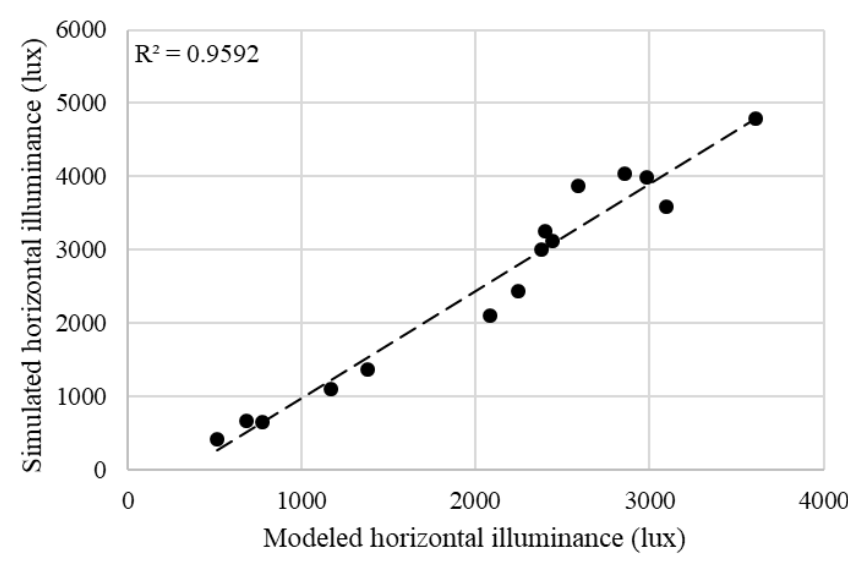

(c)

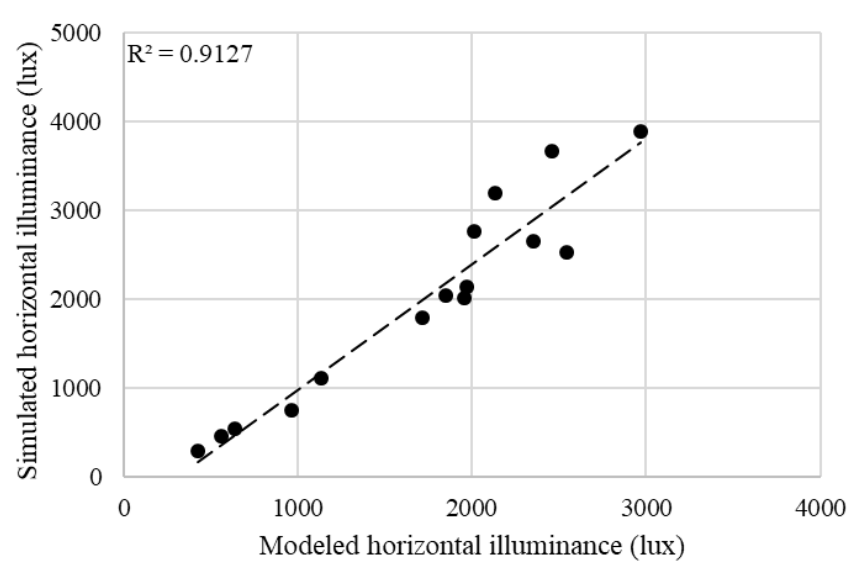

(d)

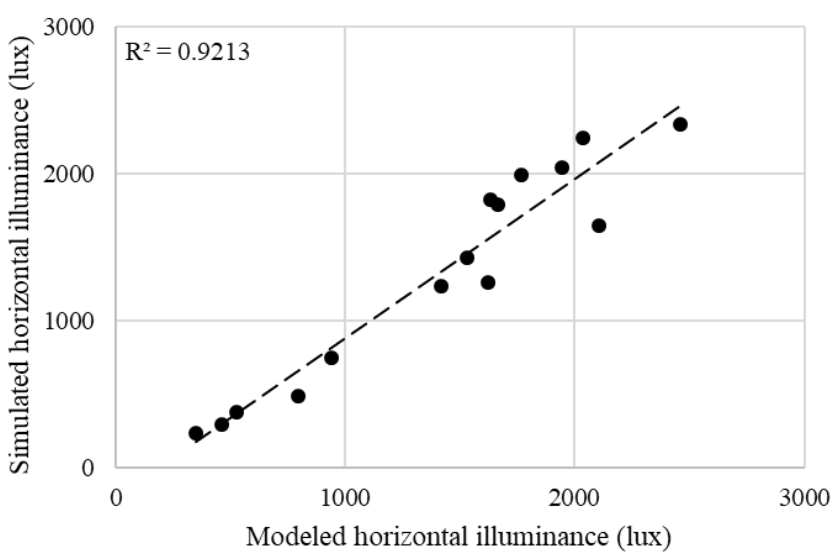

(e)

Figure 4: The SHI against MHI for an obstructed room $\left(\alpha_{U}=30^{\circ}\right)$ under the 15 CIE Standard Skies at the five points (a) $1 \mathrm{~m}$; (b) $1.5 \mathrm{~m}$; (c) $2 \mathrm{~m}$; (d) $2.25 \mathrm{~m}$; (e) $2.5 \mathrm{~m}$ from window.

It can be analyzed from the data that the cosine function of $\alpha_{U}$ times the ratios of SHI to MHI could be correlated with the sine function of the sky elements and the exterior obstruction viewed from the reference points. Through regression analysis, the following equation can be formed. 
As $\mathrm{R}^{2}$ is 0.96 , the illuminance can be estimated at different reference points.

$\cos \left(\alpha_{U}\right) \times\left(\frac{S H I}{M H I}\right)=1-4\left[\sin \left(\alpha_{w}\right)+\left(\rho_{b}-1\right) \sin \left(\alpha_{U}\right)\right]^{2}+$

$4.5\left[\sin \left(\alpha_{U}\right)+\left(\rho_{b}-1\right) \sin \left(\alpha_{U}\right)\right]-1.1$

$\left(\mathrm{R}^{2}=0.96\right)$

where $\alpha_{w}$ is the angle from the window head to the reference point; $\rho_{b}$ is the building reflectance

The VDF, PDF and their correlations were determined accordingly. Figure 5 displays the simulated vertical daylight factor (SVDF) and modeled vertical daylight factor (MVDF) at 5 points under various obstructed sky conditions $\left(\alpha_{U}=15^{\circ} ; \alpha_{U}=30^{\circ} ; \alpha_{U}=45^{\circ}\right)$. It can be observed that ratios between SVDF and MVDF are close to 1 (SVDF=0.96MVDF). It means that, the modeled results are in good agreement with the corresponding simulated data, and the proposed approach is applicable to the heavily obstructed environment.

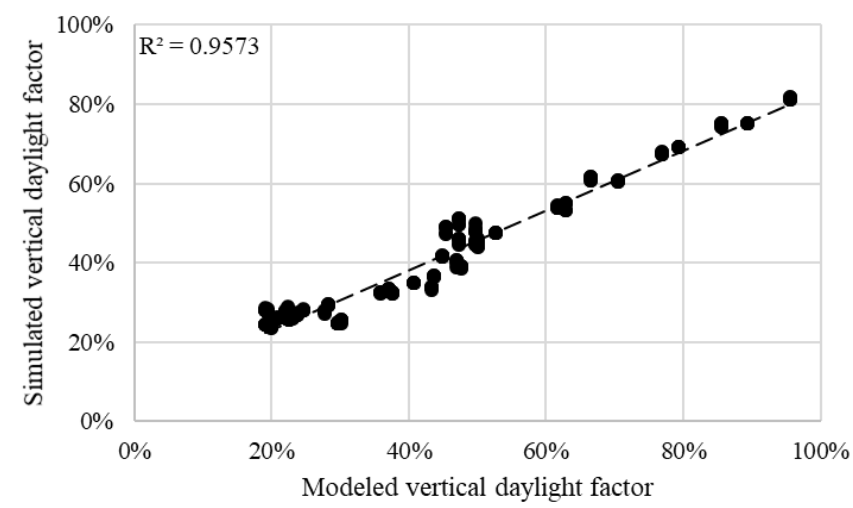

Figure 5: The SVDF against MVDF for an obstructed room under 15 CIE Standard Skies at 5 reference points.

Similarly, the data of simulated point daylight (SPDF) and modeled point daylight (MPDF) are plotted in Figure 6. With the $\mathrm{R}^{2}$ of more than 0.92 , it indicates that the sum of SC and ERC can be accurately computed by the corresponding VDF. Such issue can help the e of open loop daylight-linked lighting controls.

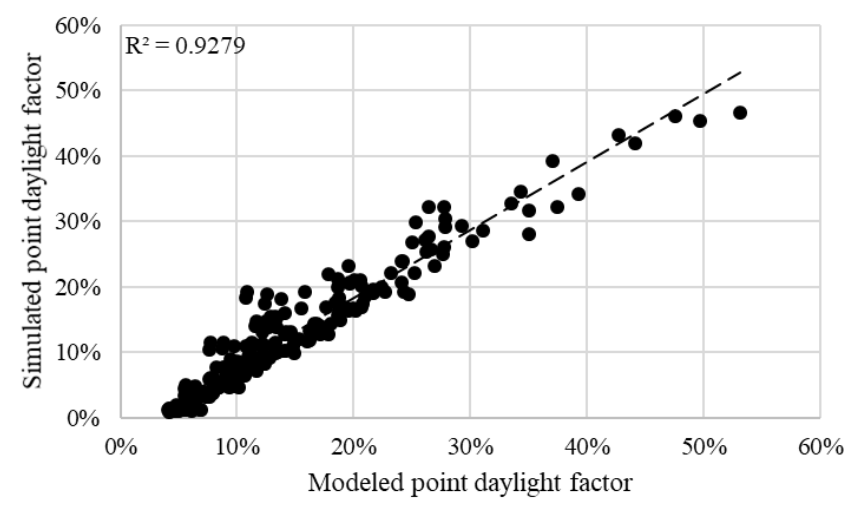

Figure 6: The SPDF against MPDF for an obstructed room under 15 CIE Standard Skies at 5 reference points.
The calculated PDF and ADF at the 6 points are plotted in Figure 7 and Eqs.10-15 give the mathematical expressions. The strength of correlations are considered very good as $\mathrm{R}^{2}$ are 1 . The point of $1 \mathrm{~m}$ has the largest PDF and ADF. The DFs drop when the point is far away from the window. At point $2.6 \mathrm{~m}$, the $\mathrm{PDF}$ is equal to $\mathrm{ADF}$. The $\mathrm{ADF}$ and $\mathrm{DF}$ at various points (PDF) under different room depths (with other parameters unchanged) were also calculated. Table 3 shows the point that ADF is equal to PDF. It indicates that the point is away from the window as the depth of the room increases. When the room length increases by $1 \mathrm{~m}$, the point increases by $0.2 \mathrm{~m}$. It shows that the required ADF can be computed using appropriate room parameters.

Table 2: The point of ADF is equal to PDF under different room depths

\begin{tabular}{|c|c|c|c|c|}
\hline Room depth & $4 \mathrm{~m}$ & $5 \mathrm{~m}$ & $6 \mathrm{~m}$ & $8 \mathrm{~m}$ \\
\hline $\begin{array}{c}\text { Point distance from the } \\
\text { window }\end{array}$ & $2.4 \mathrm{~m}$ & $2.6 \mathrm{~m}$ & $2.8 \mathrm{~m}$ & $3.2 \mathrm{~m}$ \\
\hline
\end{tabular}



Figure 7: The correlation between PDF and ADF for an obstructed room under 15 CIE Standard Skies at 6 points.

Point 1m:

$$
\mathrm{ADF}=0.36 \times \mathrm{PDF}
$$

$\mathrm{R}^{2}=1$

Point $1.5 \mathrm{~m}$ :

$$
\mathrm{ADF}=0.51 \times \mathrm{PDF}
$$$$
\mathrm{R}^{2}=1
$$

Point 2m:

$$
\mathrm{ADF}=0.71 \times \mathrm{PDF}
$$

$\mathrm{R}^{2}=1$

Point 2.25m:

$\mathrm{ADF}=0.83 \times \mathrm{PDF}$

$\mathrm{R}^{2}=1$

Point $2.5 \mathrm{~m}$ :

$\mathrm{ADF}=0.95 \times \mathrm{PDF}$

$\mathrm{R}^{2}=1$

Point 2.6m:

$$
\mathrm{ADF}=1.00 \times \mathrm{PDF}
$$$$
\mathrm{R}^{2}=1
$$

\section{Conclusions}

Calculating procedures for indoor daylight determination under the 15 obstructed CIE Standard Skies were elaborated. A number of equations, figures and charts were presented for estimating the VDF, ADF and PDF. The PDF at a point can be calculated from SC and ERC using the configuration factor principle. The finding can be used in open loop daylight-linked lighting controls. The correlations between ADF and PDF under different room depths were also estimated. The ADF can be directly determined by PDF which may be obtained via direct measurement. Equation (9) can be adopted to estimate the daylight illuminance at the reference points according to MHI. 
Daylight factors approach (DFA) has been frequently adopted within national standards in many countries and widely adopted by architects and building engineers. Recently, DFA has been extended for the 15 CIE standard skies including overcast and non-overcast conditions. It means that DFs are no longer a static matric and the drawbacks of the traditional DFA can be significantly eliminated. It can take into account the building directions, solar positions and the effect of direct and reflected sunlight. The daylight glare index and uniformity under various sky conditions and times of a day can be computed. One of the main advantages is that the DF is strongly correlated with the room parameters particularly the window area and transmittance. It would be easily to vary such parameters to meet to the criteria particularly during initial design stage when different building options and design schemes are analysed and evaluated. Computer simulations can be made after the design schemes have been finalised. Useful Daylight Illuminance (UDI) and Daylight Autonomy (DA) are useful daylight matrices but they require typical annual daylight data which may not be always available for many places. As the $15 \mathrm{CIE}$ skies represent the actual skies for many places and cover the whole probable spectrum of skies found in nature, the findings could be globally adopted and would be useful to practitioners engaged in architectural and daylighting designs and evaluations.

\section{Acknowledgement}

Work described was fully supported by a General Research Fund from the Grant Council of HKSAR [Project no. 9042504 (CityU 11209217)]. Wenqiang CHEN was supported by a City University of Hong Kong Postgraduate Studentship.

\section{References}

Cheung H.D. and Chung T.M. (2005). Calculation of the vertical daylight factor on window facades in a dense urban environment. Archit Sci Rev 48(1), 81-92.

Hopkinson, G.R., Petherbridge, P. and Longmore, J. (1966). Daylighting, Heinemann.

Hraska J. Criteria of daylighting and sunlight access in sustainable construction evaluation systems. In: Proceedings of the 5th International Conference on Solar Radiation and Daylighting. Brno University of Technology, Czech Republic, 10-11 August 2011. pp.98-103.

IES (1993). Lighting Handbook Reference \& Application. New York: Illuminance Engineering Society of North America.

International Standardisation Organisation. CIE S 011/E:2003. Spatial Distribution Daylight-CIE Standard General Sky, ISO Standard 15469: 2004, Geneva: 2004.
Kittler, R. and Darula, S. (2006). The method of aperture meridians: a sample calculation tool for applying the ISO/CIE Standard General Sky, Lighting Research and Technology 38(2), 109-22.

Li D.H.W. (2010). A review of daylight illuminance determinations and energy implications. Applied Energy 87(7), 2109-2118.

Li D.H.W., Lau C.C.S. and Lam J.C. (2003). A study of 15 sky luminance patterns against Hong Kong data. Archit Sci Rev 46(1), 61-68.

Li D.H.W., Wong S.L., Tsang C.L. and Cheung GHW. (2006). A study of the daylighting performance and energy use in heavily obstructed residential buildings via computer simulation techniques. Energy Build $38(11), 1343-1348$

Li D.H.W., Cheung G.H.W., Cheung K.L. and Lam J. C. (2009) Simple method for determining daylight illuminance in a heavily obstructed environment. Build. Environ. 44(5), 1074-1080.

Li D.H.W., Lam T.N.T. and Wu T.K.K. (2012). Estimation of average daylight factor under obstructed CIE Standard General Skies. Lighting Research \& Technology 46(2), 187-197.

Li D.H.W., Lou S., Ghaffarianhoseini A., Alshaibani K.A. and Lam J.C. (2017). A review of calculating procedures on daylight factor based metrics under various CIE Standard Skies and obstructed environments. Building and Environment 112, 29-44.

Li D.H.W., Li S., Chen W. \& Lou, S. (2018) Analysis of Point Daylight Factor (PDF) Average Daylight Factor (ADF) and Vertical Daylight Factor (VDF) under various unobstructed CIE Standard Standard Skies. IOP CONF. Series: Matericals Science and Engineering.

Littlefair PJ. (1989). Predicting hourly internal daylight illuminances for dynamic building energy modeling. Garston, UK: Building Research Establishment.

Longmore J. (1975). Daylighting: A Current View. Light and Lighting 68(3), 113-119.

Lou S, Li DHW, Lam JC, Lee Eric W.M. (2016). Estimation of obstructed vertical solar irradiation under the 15 CIE Standard Skies. Building and Environment103, 123-133.

Lynes J. and Littlefair P. (1990). Lighting energy savings from daylight: Estimation at the sketch design stage. Light Research \& Technol 22(3), 129-137.

Perez R., Seals R. and Michalsky J. (1993). All-wather model for sky luminance distribution - Preliminary configuration and validation. Solar Energy 50(3), 235345.

Yu X., Su Y. (2015). Daylight availability assessment and its potential energy saving estimation - A literature review. Renew. Sustain. Energy Rev. 52, 494-503. 


\section{Appendix}

Coefficients of Equation 8 for all 15 CIE standard Skies $\left(0<\alpha_{U}<90^{\circ}\right)$

\begin{tabular}{llllllllll}
\hline Sky. & $\boldsymbol{a}_{\boldsymbol{0}}$ & $\boldsymbol{a}_{\boldsymbol{1}}$ & $\boldsymbol{b}_{\boldsymbol{1}}$ & $\boldsymbol{\alpha}_{\boldsymbol{2}}$ & $\boldsymbol{b}_{\boldsymbol{2}}$ & $\boldsymbol{w}$ & $\boldsymbol{c}_{\boldsymbol{0}}$ & $\boldsymbol{d}_{\boldsymbol{1}}$ & $\boldsymbol{d}_{\boldsymbol{2}}$ \\
\hline 1 & 0.41 & 0 & 0 & 0 & 0 & 0 & -2.26 & 0 & 0.062 \\
2 & -2.833 & 3.200 & 3.256 & 0.129 & -1.415 & 0.458 & -2.75 & -0.002 & 0.073 \\
3 & 0.540 & 0 & 0 & 0 & 0 & 0 & -1.44 & 0 & 0.054 \\
4 & -3.453 & 4.037 & 3.807 & 0.03 & -1.73 & 0.401 & -2.31 & -0.001 & 0.070 \\
5 & 0.60 & 0 & 0 & 0 & 0 & 0 & -1.04 & 0 & 0.052 \\
6 & -5.990 & 7.074 & 5.798 & -0.383 & -2.721 & 0.401 & -2.22 & -0.001 & $0 . .73$ \\
7 & -6.780 & 7.899 & 6.809 & -0.245 & -3.262 & 0.401 & -2.21 & -0.002 & 0.074 \\
8 & 0.615 & 0.358 & 0.042 & 0.042 & 0.025 & 1.432 & -2.06 & -0.004 & 0.075 \\
9 & -4.976 & 6.230 & 5.061 & -0.306 & -2.511 & 0.401 & -2.02 & -0.001 & 0.080 \\
10 & 0.732 & 0.336 & 0.024 & 0.040 & 0.017 & 1.375 & -1.96 & -0.002 & 0.081 \\
11 & 0.801 & 0.487 & -0.032 & 0.070 & 0.015 & 1.318 & -1.86 & -0.004 & 0.082 \\
12 & 0.949 & 0.575 & -0.166 & 0.092 & -0.011 & 1.203 & -1.73 & -0.003 & 0.085 \\
13 & 1.069 & 0.784 & -0.357 & 0.134 & -0.079 & 1.089 & -1.57 & -0.007 & 0.087 \\
14 & 1.384 & 0.964 & -0.654 & 0.136 & -0.169 & 0.974 & -1.33 & -0.006 & 0.091 \\
15 & 1.503 & 1.255 & -0.833 & 0.148 & -0.259 & 0.974 & -1.14 & -0.011 & 0.093 \\
\hline
\end{tabular}

